\title{
A New method for differential protection in Power transformer
}

\author{
Harjit Singh Kainth ${ }^{1}$, Gagandeep Sharma ${ }^{2}$ \\ ${ }^{1}$ M. Tech Student, ${ }^{2}$ Assistant Professor (Electrical Engg. Department)DAV Institute of Engineering and \\ Technology, Jalandhar
}

\begin{abstract}
This paper presents design a Clark transformation based technique for protection of transformer. It improves and enhances the sensitivity of the operation of the digital differential relay that protects Power Transformers by discriminating between inrush current and fault current. The proposed method has been simulated with MATLAB/SIMULINK with different test of operations.
\end{abstract}

Key words: differential protection, Clarke transforms.

\section{Introduction}

Power transformer is one of the most important components in power system, for which manykinds of protective and monitoring schemes have been developed for many years.A power transformer is a very expensive electrical device, and its operation directly affects the performance of other equipment to which it is connected. Therefore it is necessary to use efficient protection schemes and monitoring systems in order to ensure its physical integrity, as well as a long operating lifetime. The protection of Transformers is critical phenomenon. Traditionally, transformer protection methods that use its terminal behaviour are based on differential protection is considered as a most widely used technique to perform the protection function. The differential protection scheme can be used to protect both the primary and secondary windings of a three-phase transformer against faults. The method fundamentally based on the discrimination between faults and other operating conditions[1].

The Power Transformer protection method should avoid and block the tripping of Differential relay during Magnetizing Inrush and should rapidly operate the relay tripping during internal faults. As a result it is essential to choose a proper identification scheme which can discriminate and distinguishes the Magnetizing inrush and internal fault current while a new Power Transformer is being installed by power companies.

The scholars have studied a lot, some conventional techniques to distinguish between inrush current and internal fault currents in transformers are reported here based on different principles.

The second harmonic restraint method is the most common one used by various relay manufacturers and application engineers. There are a small number of variations of harmonic restrained differential protection. In [2] author investigates the factors affecting the second harmonic ratio in inrush current. Fifth Harmonic blockade technique is proposed in [3].The wavelet Packets (WPT) algorithm approach for determining different types of currents in [4]. The combination of hidden Markov models (HMM) and wavelet transform (WT) to discriminate between magnetizing inrush currents and internal faults is proposed in [5].Then the techniques to increase consistency, speed and robustness of existing digital relays come into existence are ANN approach, Fuzzy logic and adaptive fuzzy-Neuro approaches. In [6] the author recommendedfuzzy logic for internal fault detection in differential protection. In [7] the author developed a new method of discrimination based on artificial neural network. The work reported in [8] demonstrated the use of an Artificial Neural Network (ANN) as a pattern classifier for differential relay operation. Under ANN, one strong method to discriminate between inrush and internal fault current is Probabilistic neural network (PNN) [9]. The paper [10] presents a new inrush detector algorithm for differential protection of power transformer based on the fuzzy-Neuro method.The paper [11] work on Fuzzy-Neuro techniques in order to ensures relay stability against sympathetic inrush, external faults, magnetizing inrush over excitation conditions and its action on internal faults.

\section{A. Definition of differential protection}

The fundamental operating principle of transformer differential protection is based on comparison of the transformer primary and secondary winding currents. For an ideal transformer, having a 1:1 ratio and neglecting magnetizing current, the currents entering and leaving the transformer must be equal. The differential relay actually compares between primary current and secondary current of power transformer, if any unbalance encountered in between primary and secondary currents the relay will actuate and inter trip both the primary and secondary circuit breaker of the transformer.

Consider that you have one transformer which has primary rated current $I_{P}$ and secondary currentI $I_{S}$.If you install $\mathrm{CT}$ of ratio $\mathrm{I}_{\mathrm{P}} / 1 \mathrm{~A}$ at primary side and similarly, $\mathrm{CT}$ of ratio $\mathrm{I}_{\mathrm{S}} / 1 \mathrm{~A}$ at secondary side of the transformer. The secondaries of these both CTs are linked together in such a manner that secondary currents of 
both CTs will oppose each other. This can be explain in other way as, the secondary's of both CTs should be connected to same current coil of differential relay in such a opposite manner that there will be no resultant current in that coil in normal working condition of the transformer. But if any serious fault happens inside the transformer due to which the normal ratio of the transformer disturbed then the secondary current of both transformer will not remain the same and one resultant current will flow through the current coil of the differential relay, which will trigger the relay and inter trip both the primary and secondary circuit breakers.

\section{B. Mathematical model}

The current of the Current transformer located in the primary side of the power transformer

$$
\mathrm{I}_{1}=\frac{\mathrm{I}_{\mathrm{P}}}{\mathrm{N}_{1}}
$$

Where:

$I_{P}:$ The primary side current of the power transformer,

$\mathrm{I}_{1}$ : The secondary side current ofCT 1

$\mathrm{N}_{1}$ :The number of turns in the secondary side of $\mathrm{CT}_{1}$

In the same manner for the CT located at the secondary side of the power transformer, then the CT secondary current is:

$$
\mathrm{I}_{2}=\frac{\mathrm{I}_{\mathrm{S}}}{\mathrm{N}_{2}}
$$

Where:

$\mathrm{I}_{\mathrm{S}}$ : The primary side current of the power transformer,

$\mathrm{I}_{2}:$ The secondary side current ofCT 1

$\mathrm{N}_{2}$ : The number of turns in the secondary side of $\mathrm{CT}_{2}$

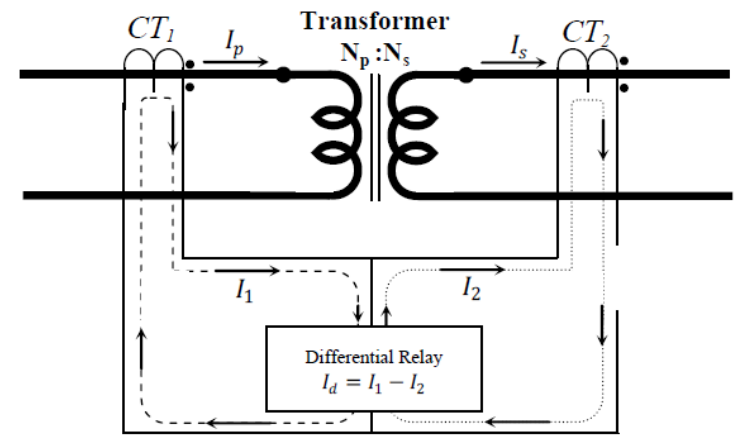

Figure 1. Differential protection for single phase two winding transformer

Since the differential current is: $I_{d}=I_{1}-I_{2}$ then, from equation (1) and equation (2) the differential current flowing in the relay operating coil current $\mathrm{I}_{\mathrm{d}}$ can be calculated as;

So,

$$
\mathrm{I}_{\mathrm{d}}=\frac{\mathrm{I}_{\mathrm{P}}}{\mathrm{N}_{1}}-\frac{\mathrm{I}_{\mathrm{S}}}{\mathrm{N}_{2}}
$$

If there is no internal fault occurring within the power transformer protected zone, the currents $\mathrm{I}_{1}$ and $\mathrm{I}_{2}$ are assumed equal in magnitude and opposite in direction. That means the differential current $\mathrm{I}_{\mathrm{d}}=0$ as presented in figure 2 . The primary and secondary side current of the power transformer are related to each other by equation (4);

$$
\frac{I_{P}}{I_{S}}=\frac{N_{S}}{N_{P}}
$$

Where:

$\mathrm{N}_{\mathrm{P}}$ and $\mathrm{N}_{\mathrm{S}}$ : primary and secondary side turns of the power transformer, correspondingly

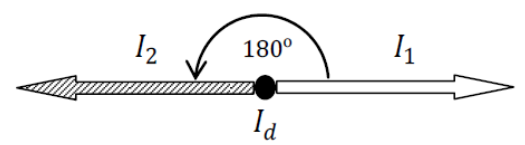

Figure 2.Output currents of the CTs are equal in magnitude and opposite in direction 
If there is any fault in the power transformer protected zone, the currents $I_{1}$ and $I_{2}$ are no longer equal in magnitude and opposite in direction. That means the differential current $\mathrm{I}_{d}=\mathrm{I}_{\mathrm{d}} \angle \theta$ has a significant value as shown in figure 3.

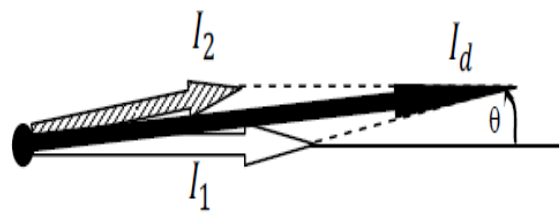

Figure 3. Output currents of the CTs are not equal in magnitude and not opposite in direction

The amount of current $\mathrm{I}_{\mathrm{d}}=\mathrm{I}_{\mathrm{d}} \angle \theta$ induces the relay operating coil to operate in order to send a trip signal to the circuit breakers to isolate the transformer.

\section{Proposed Methodology}

This method is possible due to the first woman obtaining the Master degree in electrical engineering at the MIT. She was also the first woman hired by General Electric as an electrical engineer in the United States. Also in 1948 was the first woman nominated as Fellow at AIEE. The name of this extraordinary woman was Edith Clarke which method of transforming a three phase signal into a two phase signal is called: "Clarke's transform".

The Clarke's transformation is a well-known transformation presented by Edith Clarke in [42]. The Clarke transformsutilized three-phase currents: $i_{a}, i_{b}$ and $i_{c}$ to calculate currents in the two-phase orthogonal stator axis: $\mathrm{i}_{\mathrm{a}}$ and $\mathrm{i}_{\mathrm{b}}$.

\section{A. Mathematical Clarke transforms.}

The mathematical transformation of Clarke transform modifies three-phase system to a two-phase orthogonal system:

$$
\begin{gathered}
\mathrm{i}_{\alpha}=\frac{2}{3} \mathrm{i}_{\mathrm{a}}-\frac{1}{3}\left(\mathrm{i}_{\mathrm{b}}-\mathrm{i}_{\mathrm{c}}\right) \\
\mathrm{i}_{\beta}=\frac{2}{\sqrt{3}}\left(\mathrm{i}_{\mathrm{b}}-\mathrm{i}_{\mathrm{c}}\right) \\
\mathrm{i}_{\beta}=\frac{2}{3}\left(\mathrm{i}_{\mathrm{a}}+\mathrm{i}_{\mathrm{b}}+\mathrm{i}_{\mathrm{c}}\right)
\end{gathered}
$$
system.

Withi $\mathrm{i}_{\mathrm{a}}$ and $\mathrm{i}_{\mathrm{b}}$ components in an orthogonal reference frame and $\mathrm{i}_{\mathrm{o}}$ the homopolar component of the

In many applications, the homopolar component is absent or is less important. In this way, in absence of homopolar component the space vector $\mathrm{u}=\mathrm{u}_{\mathrm{a}}+\mathrm{ju}_{\mathrm{b}}$ represents the original three-phase input signal.

Consider now a particular case with $i_{\alpha}$ superposed with $i_{a}$ and $i_{a}+i_{b}+i_{c}$ is zero, in this condition $i_{a}, i_{b}$ and $i_{c}$ can be transformed to $i_{\alpha}$ and $i_{\beta}$ with following mathematical transformation [12]:

$$
\begin{gathered}
\mathrm{i}_{\alpha}=\mathrm{i}_{\mathrm{a}} \\
\mathrm{i}_{\beta}=\frac{1}{\sqrt{3}} \mathrm{i}_{\mathrm{a}}+\frac{2}{\sqrt{3}} \mathrm{i}_{\mathrm{b}} \\
\mathrm{i}_{\mathrm{a}}+\mathrm{i}_{\mathrm{b}}+\mathrm{i}_{\mathrm{c}}=0
\end{gathered}
$$

B. Methodology

1. Very first we measuring the three phase current on both sides of transformer.

2. Then performing Clark transformation on these phase currents. The main idea of using Clarke's transformation is to carry out in a pattern-recognition process to discriminate certain conditions of transformers.

3. Then we find the difference between phase to phase transformed current. These giving the information about the pattern difference between phase to phase current.

4. By the analysis of this we developed a lookup function which is monitoring as: 
a. If the absolute instantaneous values of difference of transformed current for phase A and B are greater than $20 \mathrm{amp}$ and for phase $\mathrm{C}$ is greater than $1 \mathrm{e}-3 \mathrm{amp}$ then trips has to be released.

OR

b. If the absolute instantaneous values of difference of transformed current for phase $\mathrm{A}$ and $\mathrm{B}$ are greater than $50 \mathrm{amp}$ and for phase $\mathrm{C}$ is greater than 1e-4 amp then trips has to be released.

The proposed model requires very less hardware than as compared to the base paper.

\section{Results}
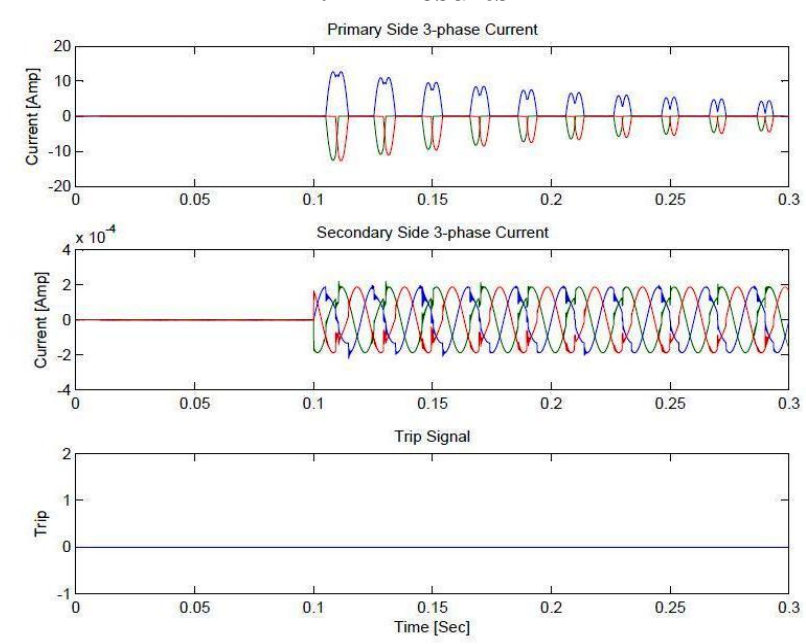

Figure 4.1: Magnetizing inrush
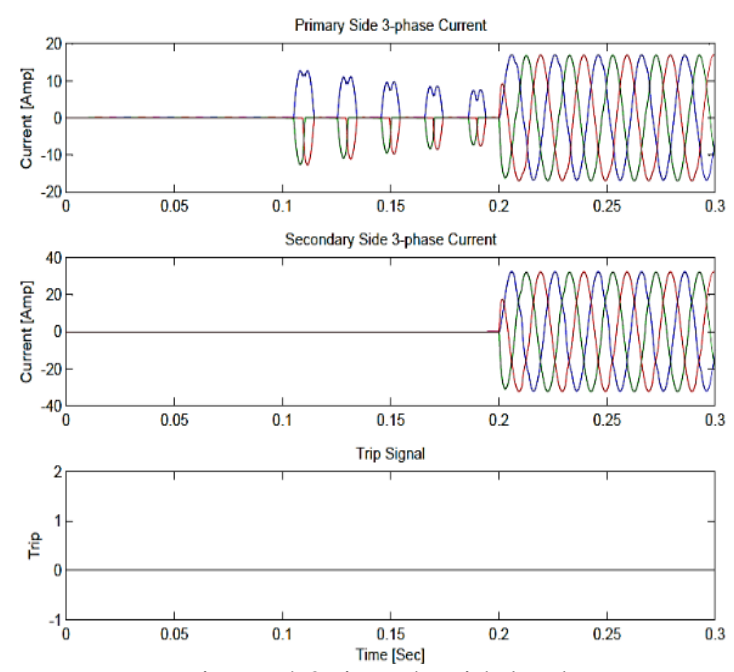

Figure 4.2: inrush with load
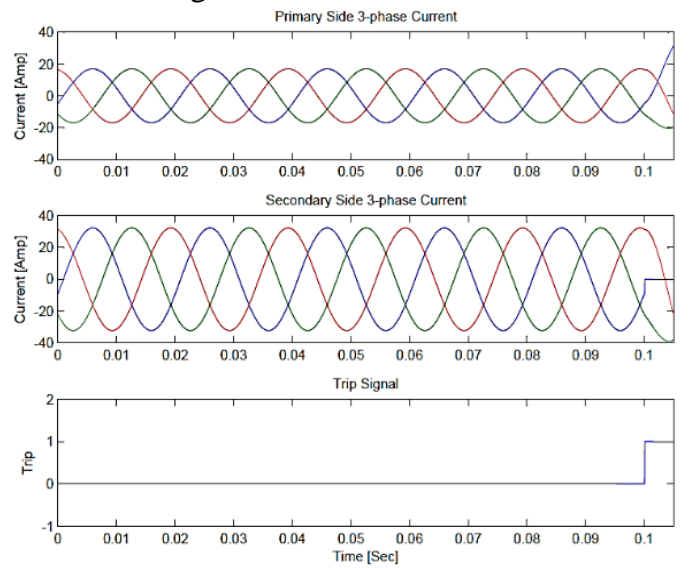

Figure 4.3: A-G fault 

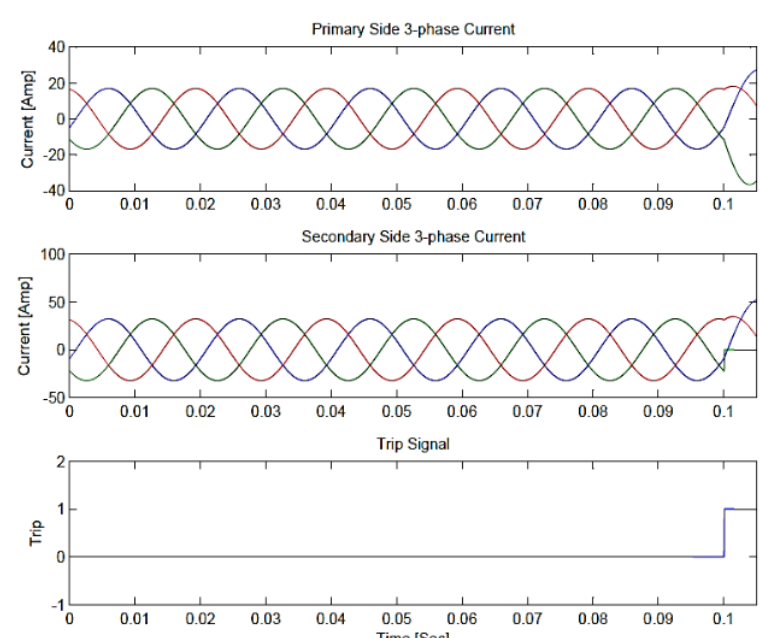

Figure 4.4: B-G fault
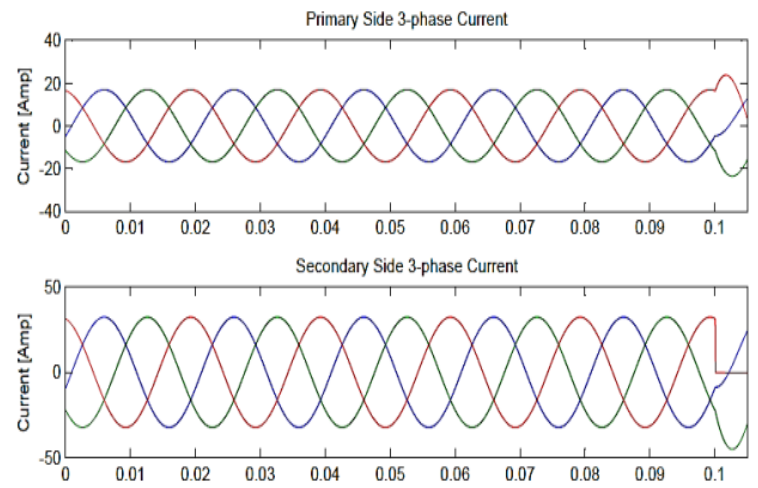

Trip Signal

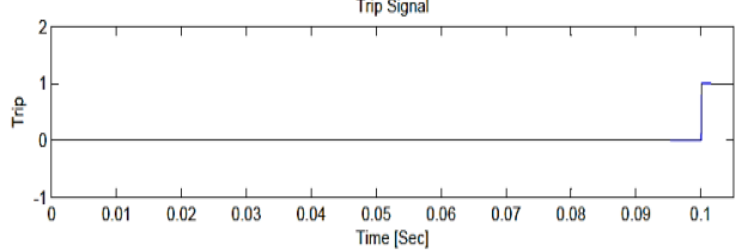

Figure 4.5: C-G fault
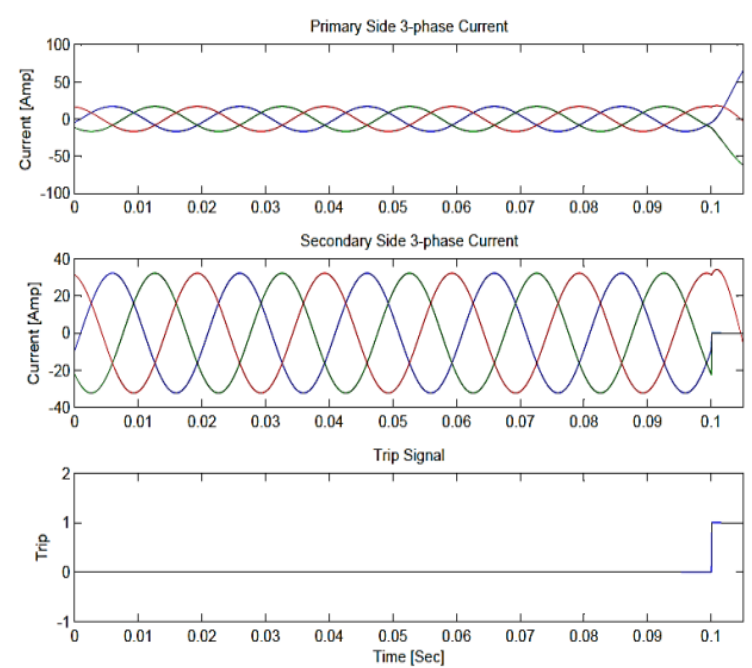

Figure 4.6: A-B fault 

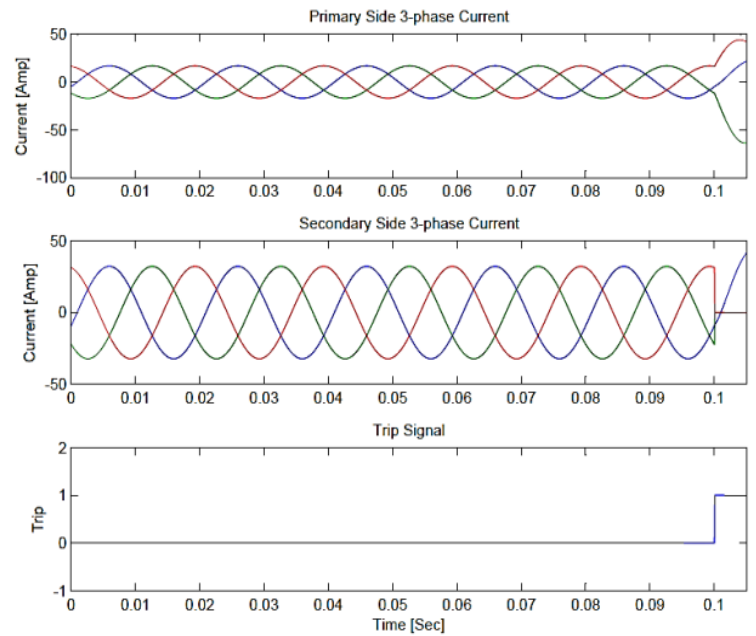

Figure 4.7: B-C fault
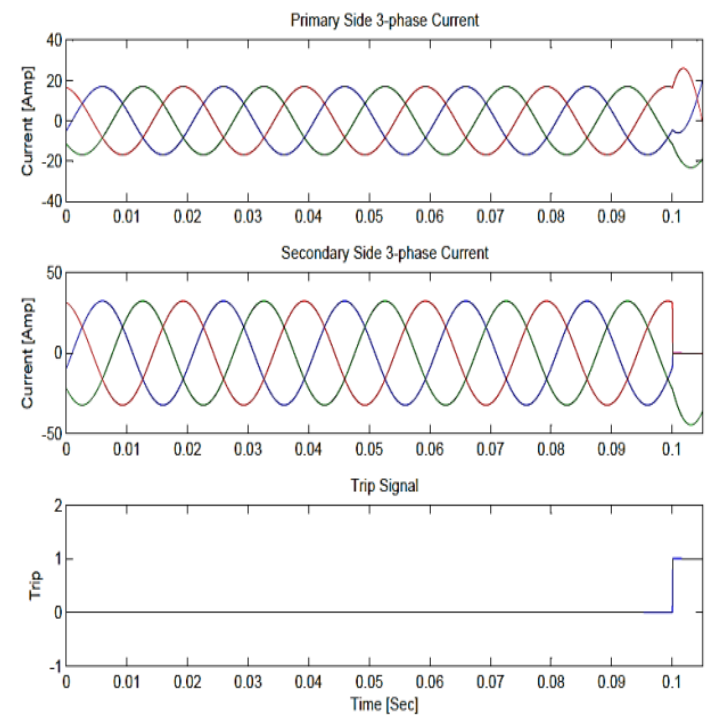

Figure 4.8: C-A fault
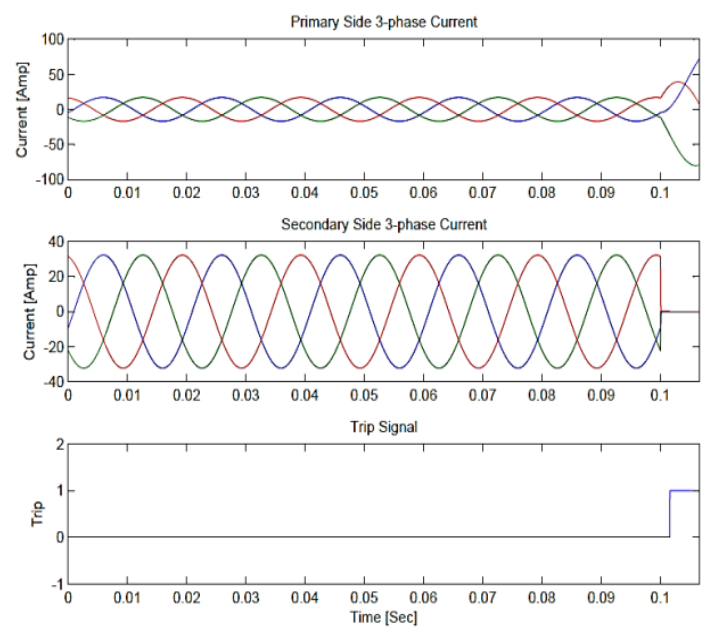

Figure 4.9: ABC-G fault 


\section{Conclusion}

A MATLAB simulation of a laboratory power transformer is presented in this paper. As shown in the results this simulation is tested in many cases and for all cases it gave satisfactory results. This trip time $(5.0000 \mathrm{e}-005 \mathrm{sec})$ is satisfactory in order to ensure that the algorithm will give a proper decision to discriminate between a fault current and an inrush current. On the other hand the relay is restrained in all the cases for the inrush current, normal load current or the external fault current.

\section{References}

[1]. Blackburn, J.L., Domin, T.J.: 'Protective relaying principles and applications', 2007.

[2]. Jialong Wang, "Analysis of transformer inrush current and comparison of harmonic restraint methods in transformer protection" Protective Relay Engineers, 2008 61st Annual Conference 1-3 April 2008

[3]. OuahdiDris, Farag. M. Elmareimi and RekinaFouad, "Transformer differential protection scheme with internal faults detection algorithm using second harmonics restrain and fifth harmonics blocking logic"

[4]. Iswadi HR , RedyMardiana, "Differential power transformer protection techniques using the wavelet packet transform approach" Proceedings of the International Conference on Electrical Engineering and Informatics Institute Teknologi Bandung, Indonesia June 17-19, 2007

[5]. SaeedJazebi, BehroozVahidi and SeyedHossenien "A Novel Discriminative Approach Based on Hidden Markov Models and Wavelet Transform to Transformer Protection" Journal imulationVol 86 Issue 2 Feb 2010

[6]. ImanSepehri Rad, MostafaAlinezhad, SeyedEsmaeelNaghibi and MehrdadAhmadiKamarposhti "Detection of Internal Fault in Differential Transformer Protection Based on Fuzzy Method", American Journal of Scientific Research ISSN 1450-223X Issue 32(2011), pp. 17-25

[7]. SRParaskar, M.A.Beg, G.M.Dhole, "Discrimination between Inrush and Fault in Transformer: ANN Approach" International Journal of Advancements in Technology Vol 2, No 2 (April 2011)

[8]. Venkateshan and M. Senthil Kumar, "Power transformer differential protection with neural network based on symmetrical component" International journal of communication and Engineering, Vol 06 No.6 2012

[9]. Manoj Tripathy, R P Maheshwari and H K Verma," Power Transformer Differential Protection based on optimal probabilistic Neural Network, IEEE transactions on power Delivery, Vol 25, No 1, 2010

[10]. H. KhorashadiZadeh, Mr Aghaebrahimi, „A neuro- fuzzy technique for discrimination between internal faults and magnetizing inrush currents in transformer" Iranian Journal of Fuzzy Systems Vol. 2, No. 2 , (2005)

[11]. Manoj Tripathy, R P Maheshwari and H K Verma, "Neuro- fuzzy technique for power transformer protection" Electric power components and system 2008.

[12]. "Clarke \& Park Transforms on the TMS320C2xx", Application Report.

\section{AUTHOR'S PROFILE:}

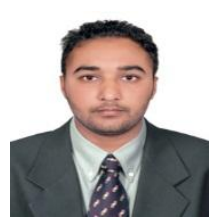

Harjit Singh KainthReceived B.tech degree in Electrical Engg.from Guru Nanak DevEngg. College Ludhiana.Presently pursuing my M.tech degree from DAVIET Jalandhar.

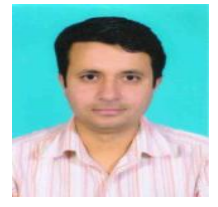

Gagandeep Sharma Received B-tech degree and M.tech Degree in Electrical engineering from Guru Nanak DevEngg. College, Ludhiana.Currently, he is pursuing his Ph.D from SLIET Longolwal. He is working as Assistant professor in Electrical Department in DAVIET from last 10 years. His main research interests include Electrical machines and Power Electronics. 